\title{
A comparison of Ti-6Al-4V in-situ alloying in Selective Laser Melting using simply-mixed and satellited powder blend feedstocks
}

Marco Simonelli a, Nesma T. Aboulkhair ${ }^{\text {a }}$, Philip Cohen ${ }^{\text {a }}$, James W. Murray ${ }^{\text {b }}$, Adam T. Clare ${ }^{\text {a }}$, Chris Tuck $^{\text {a }}$ and Richard J. M. Hague ${ }^{\text {a }}$

${ }^{a}$ Centre for Additive Manufacturing, Faculty of Engineering, University of Nottingham, NG $72 R D$, $U K$

${ }^{b}$ Advanced Manufacturing, Faculty of Engineering, University of Nottingham, $N G 72 R D, U K$

Corresponding author: Dr Marco Simonelli, Marco.Simonelli@ nottingham.ac.uk

\begin{abstract}
In-situ alloying within laser powder-bed fusion, specifically Selective Laser Melting (SLM), has been investigated for the formulation of novel alloys from elemental powders to extend the benefits offered by these technologies. Inadequate preparation of the powder feedstock prior to in-situ alloying can yield inhomogeneous microstructures, often deteriorating the mechanical performance of the deposited parts. The present work was designed to assess the use of the 'satelliting' method to create powder feedstocks for in-situ laser powder-bed fusion. The research was carried out on Ti-6Al-4V. Ti$6 \mathrm{Al}-4 \mathrm{~V}$ feedstocks obtained by mixing or satelliting elemental powders were investigated and compared to a reference pre-alloyed material. The processability of the different feedstocks was assessed by comparing the microstructure of the deposits originating from the different powder blends. Results show that the powder percolation and particle size distribution of the feedstocks translate in deposited microstructures exhibiting different porosity, elemental segregation, and average grain size, revealing the impact of the powder blend characteristics on the laser energy absorbance and solidification of the alloy. This study provides fundamental insights of how to formulate powder feedstock and aims to support future research activities on the design and development of new alloys for use in powder-based additive manufacturing.
\end{abstract}




\section{Graphical abstract}

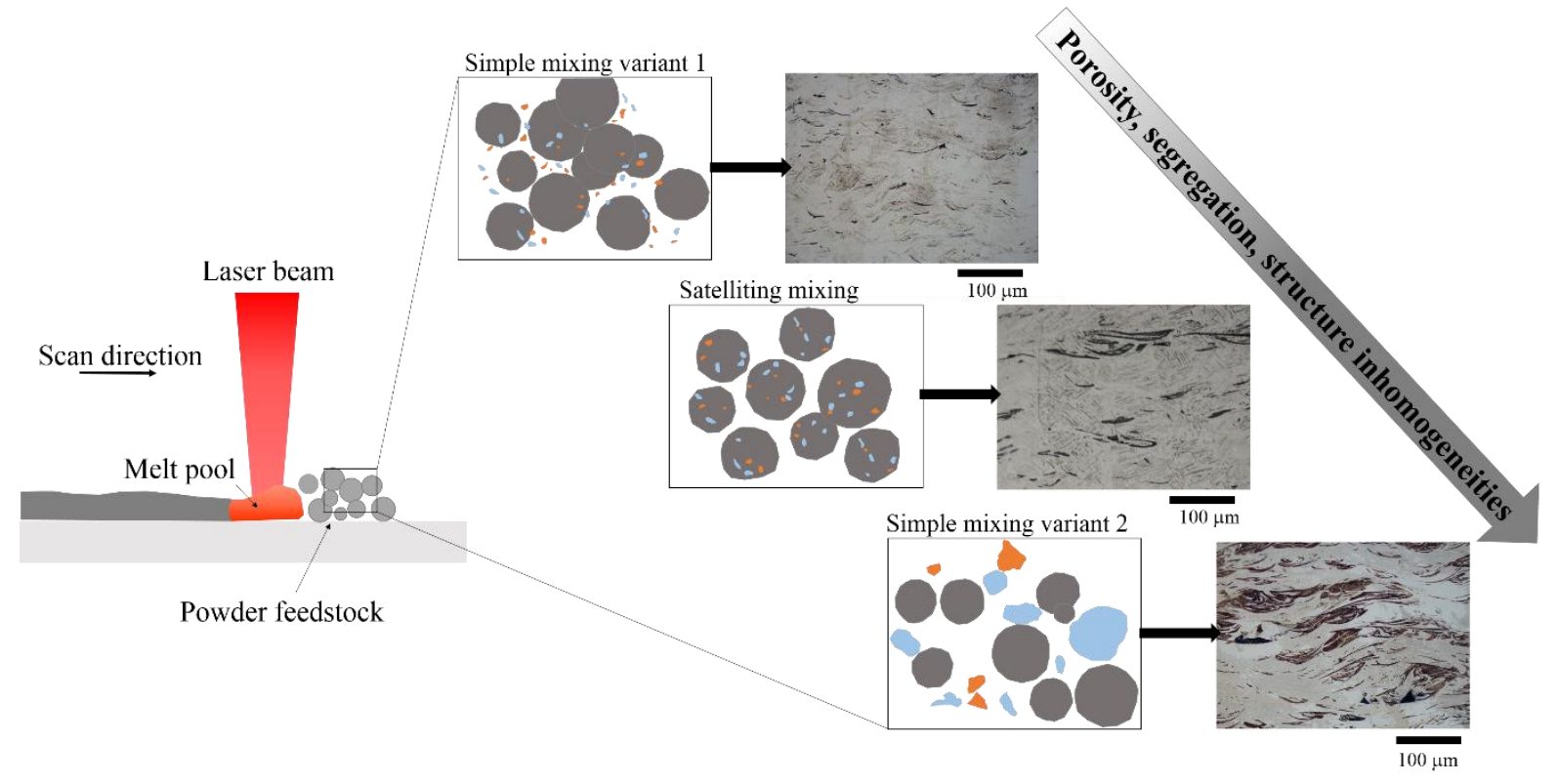

\section{Highlights}

- Satelliting mixing is proposed for preparing powder feedstocks for AM.

- Satelliting allows the creation of blended feedstocks of improved homogeneity.

- Sample homogeneity is affected by particle size distribution and powder mixing technique.

\section{Keywords}

Selective Laser Melting (SLM); Ti-6Al-4V; Powder feedstock; In-situ alloying; Satelliting; Additive Manufacturing 


\section{Introduction}

Selective Laser Melting (SLM) is a laser powder-bed fusion metal Additive Manufacturing (AM) technique that has been the subject of academic and industrial interest over the last two decades; thanks to the wide range of advantages offered in comparison to other traditional manufacturing methods [1]. This has resulted in a good understanding of the process-material-properties relationship of several important conventional alloys including Al-Si12, Al-Si10-Mg, 316L stainless steel, and Ti$6 \mathrm{Al}-4 \mathrm{~V}$, as well as the solidification mechanisms of these materials under the SLM manufacturing conditions [2-5].

Owing to the large thermal gradients and iterative thermal cycles intrinsic to the SLM process, the typical microstructure of most traditional alloys exhibits undesirable features such as inhomogeneity of grain size and phase distribution, micro-segregation, cracking, and mechanical anisotropy [6-8]. As such, there is a need to discover new feedstock compositions more suitable for SLM, in order to change the solidification of the alloy by manipulating the elemental composition of the printing material and thereby accommodate the dynamics of the process and improve the resulting microstructure. This has prompted research into flexible and cost-effective methodologies to create and study new materials. In-situ alloying, which involves the use of the laser beam to directly melt and create an alloy from elemental powder mixtures, is an example of such research.

There are several studies in which the concept of in-situ alloying during SLM and its potential use for material screening and optimisation have been demonstrated. Vrancken et al. [9] investigated the role of Mo on the microstructural evolution of a novel beta titanium composite, showing that the addition of 10 wt.\% Mo to Ti-6Al-4V can yield an increase in the strength and ductility of the material.

Sistiaga et al. [7] demonstrated that the addition of Si to Al7075 yields a change in the latter stage of the solidification mechanism of the alloy and can thereby reduce/eliminate hot-tear cracking. Similarly, it has been shown that the addition of $\mathrm{Zr}$ to $\mathrm{Al}-\mathrm{Cu}-\mathrm{Mg}$ powders creates a novel feedstock with improved resistance to hot-tear cracking during SLM [10]. In developing new alloys for AM, Guo et al. and Yadroitsev at al. also performed the in-situ alloying of $\mathrm{Cu}$ and Ti-6Al-4V and demonstrated a viable method to produce a novel biomaterial with antibacterial properties [11, 12]. Similarly, Pd additions to Ti-6Al-4V have shown to improve the corrosion resistance of the alloy in an environment similar to that of human bodies [13]. In addition, Vora et al. [14] demonstrated that in-situ alloying of constituents of an eutectic alloy (Al-12Si for example) could be used as a technique to reduce the supporting structures for overhanging geometries.

Despite these advances, parts deposited from the mechanically-mixed elemental powders (hereafter referred to as "simply-mixed") can suffer from macro-segregation of the alloy constituents originating primarily from inhomogeneities in the initial feedstock. Prior work has demonstrated that the mixing 
of the alloying elements can be facilitated by tuning the laser process parameters (for example by increasing the laser power or decreasing the laser scan speed $[11,14,15])$, but in most instances, difficulty has been demonstrated by: the poor repeatability of in-situ alloy synthesis; un-molten powders and regions in the produced parts having compositions that are highly inhomogeneous. The microstructural homogeneity depends significantly on the degree of mixing of the feedstock relative to the beam spot size characteristic of the process [13,15-17] and ensuring adequate mixing of the feedstock for processes based on highly condensed beams, such as are found within SLM, remains a significant challenge. Methodologies to ensure the preparation of the appropriate quality of powder mixtures that respond well to powder-bed fusion represent therefore an important aspect of research. In this work, a novel powder mixing technique, referred to as satelliting [18], is evaluated to produce Ti-6Al-4V feedstock for SLM directly from elemental powders only. Satelliting involves coating a larger parent particle, the carrier, with smaller "satellite" particles, and has been recently proposed as a technique capable of increasing the feedstock homogeneity over simple mechanical mixing whilst maintaining the same recyclability and cost benefits $[19,20]$. Satellited powder feedstock is firstly compared to the widely used pre-alloyed reference and to feedstock obtained by simple-mixing alloying elements. The processability of the feedstocks and the microstructure of the corresponding deposited parts is assessed. Since the SLM of pre-alloyed Ti-6Al-4V is well understood, the choice of this processing material improves understanding of how the elemental powder mixing techniques affect the synthesis of the alloys during SLM. This study aims to increase the understanding regarding in-situ alloying during SLM and find relevance in the wider context of alloy design for powder-bed fusion and beam deposition AM.

\section{Materials \& Methods}

\subsection{Reference powders: pre-alloyed Ti-6Al-4V}

Pre-alloyed plasma atomised Ti-6Al-4V powders of spherical morphology and with size distribution $\mathrm{D}_{10}=22.1 \mu \mathrm{m}, \mathrm{D}_{50}=33.5 \mu \mathrm{m}$ and $\mathrm{D}_{90}=49.9 \mu \mathrm{m}$ were provided by LPW Technology and used in this study as a reference material.

\subsection{Simple-mixing of Ti-6Al-4V}

Two simply mixed feedstocks were formulated. To minimise particle percolation, simple-mixing was firstly carried out on elemental powders of similar size distributions (simply mixed 1). Elemental Ti (purchased from LPW Technology with a nominal size distribution $\mathrm{D}_{10}=43.1 \mu \mathrm{m}, \mathrm{D}_{50}=57.0 \mu \mathrm{m}$, $\mathrm{D}_{90}=74.9 \mu \mathrm{m}$ ) was first sieved to obtain a size range of $45-75 \mu \mathrm{m}$ appropriate for SLM. Al powders with a maximum particle size of $60 \mu \mathrm{m}$ were purchased from GoodFellow Cambridge Ltd. Al powders were sieved at $45 \mu \mathrm{m}$ and the particles smaller than $45 \mu \mathrm{m}$ were discarded from the experiment. $\mathrm{V}$ powders with a nominal particle size distribution $\mathrm{D}_{10}=6.39 \mu \mathrm{m}, \mathrm{D}_{50}=21.2 \mu \mathrm{m}$ and $\mathrm{D}_{90}=45.8 \mu \mathrm{m}$ were sourced from GoodFellow Cambridge Ltd and used in the mixture. The three elemental powders were then combined in a weight proportion of 90:6:4, respectively, and then mixed 
in a TURBULA® Shaker-Mixer for 20 minutes until no visible agglomerates could be seen, and the mixture appeared to have a homogeneous colour tone. Elemental Ti (size range comprised between 45 $-75 \mu \mathrm{m}$ ) was then simply mixed with finer $\mathrm{Al}$ and $\mathrm{V}$ particles (size distribution $\mathrm{D}_{10}=2.8 \mu \mathrm{m}, \mathrm{D}_{50}=6.2$ $\mu \mathrm{m}$ and $\mathrm{D}_{90}=12.2 \mu \mathrm{m}$ and $\mathrm{D}_{10}=6.39 \mu \mathrm{m}, \mathrm{D}_{50}=21.2 \mu \mathrm{m}$ and $\mathrm{D}_{90}=45.8 \mu \mathrm{m}$, respectively) to realise a third type of feedstock (simply mixed 2). Finer alloying elements enable a superior powder-bed density and better distribution of the $\mathrm{Al}$ and $\mathrm{V}$ in the mixture although particle size difference might result in undesirable segregation.

\subsection{Satellite mixing of Ti-6Al-4V}

The satellited Ti-6Al-4V feedstock was lastly prepared so that Ti particles (base metal) could be decorated with smaller $\mathrm{Al}$ and $\mathrm{V}$ powders (alloying elements) according to the weight proportions of 90:6:4, respectively. Elemental Ti was firstly sieved to obtain a size range comprised between $45-75$ $\mu \mathrm{m}$ to guarantee that enough Ti particles could act as carriers. The Al powders that were used for the satellite mixing had a size distribution $\mathrm{D}_{10}=2.8 \mu \mathrm{m}, \mathrm{D}_{50}=6.2 \mu \mathrm{m}$ and $\mathrm{D}_{90}=12.2 \mu \mathrm{m}$ and were purchased from GoodFellow Cambridge Ltd. The same V powders that were used for the simply-mixed feedstock were also used for satellite mixing due to a lack of commercial availability of smaller $\mathrm{V}$ particles. The satelliting process was carried out in $40 \mathrm{~g}$ batches and, as detailed in [19, 20], consisted of four steps. Firstly, Ti, Al, and V were dry mixed to break powder agglomerates and disperse the elements in a homogeneous mix. This was continued until no visible agglomerates could be seen and the mixture appeared to have a single colour tone throughout. Secondly, Polyvinyl Alcohol (PVA) diluted at $2.7 \%$ in distilled water was introduced to the dry mix. Wet mixing was carried out until the liquid was dispersed throughout the mixture. The wet mixture was then agitated in a TURBULA® Shaker-Mixer to break large lumps of wet agglomerates. Finally, the mix was oven-dried at $100^{\circ} \mathrm{C}$ for 15 hours to remove any moisture and sieved at $75 \mu \mathrm{m}$ to remove any remaining agglomerates and facilitate the spreading of an even powder layer during SLM.

\subsection{Selective laser melting of the prepared mixtures}

Prior to SLM the flowability of the different powder feedstocks was characterised according to ASTM standard B213. A Realizer SLM50 was used to process the prepared mixtures. This is a commercial system equipped with a fibre laser with a maximum output power of $100 \mathrm{~W}$. The samples were built on Ti-6Al-4V build plates heated to $200^{\circ} \mathrm{C}$. The process chamber atmosphere was regulated with circulating Ar to keep oxygen levels below $0.5 \%$. Cubic samples of $5 \mathrm{~mm}$ side dimension were fabricated across the build-plate to ensure that the position of the cubes did not affect results. The process parameters ( $82 \mathrm{~W}$ laser power, $90 \mu \mathrm{m}$ hatch spacing, $40 \mu \mathrm{m}$ layer thickness, and $500 \mathrm{~mm} / \mathrm{s}$ scan speed) were constant throughout the study, and were derived from previous studies on prealloyed Ti-6Al-4V. Each layer was scanned twice, rotating $90^{\circ}$ between each two consecutive layers. 
The melt pool size formed under these processing conditions was estimated from cross sectional images of scan tracks of pre-alloyed Ti-6Al-4V of the substrate.

\subsection{Specimen characterisation}

Metallographic specimens were prepared from the SLM samples by carrying out standard mechanical grinding to obtain a polished cross-section following the standard metallurgical preparation. Kroll's reagent $\left(2 \mathrm{ml} \mathrm{HF}, 6 \mathrm{ml} \mathrm{HNO}_{3}\right.$, and $92 \mathrm{ml} \mathrm{H}_{2} \mathrm{O}$ ) was used to etch the samples to reveal the microstructure. The etched samples were imaged using a Nikon Eclipse LV100ND optical microscope. Pore analysis was conducted through image processing of the optical micrographs using automatic thresholding on the open source software ImageJ. Electron Backscatter Diffraction (EBSD) coupled with Energy Dispersive Spectroscopy (EDS) was carried out on a JEOL 7100F FEG-SEM to resolve the grain structure, the elemental distribution, and crystallographic texture of the samples. The EBSD analysis was carried out on the frontal planes of the deposited structure (xz-plane in agreement with standard [21]) with a step size of $0.2 \mu \mathrm{m}$. The inverse pole figures were plotted along the z-axis (building direction).

The phase identification in the solid samples was investigated by X-Ray Diffraction (XRD) using a Bruker D500 X-ray diffractometer using $\mathrm{Cu}$ k-alpha radiation (0.15406 nm wavelength). A step time of $20 \mathrm{~s}$ and step size of $0.03^{\circ}$ were used for all scans.

\section{Results}

\subsection{Analysis of the powder feedstocks prepared for SLM}

Figure 1 shows a comparison of the powder feedstocks prior to SLM and a schematic to-scale representation (red circle) of the melt pool size formed under the process conditions used in this study. 

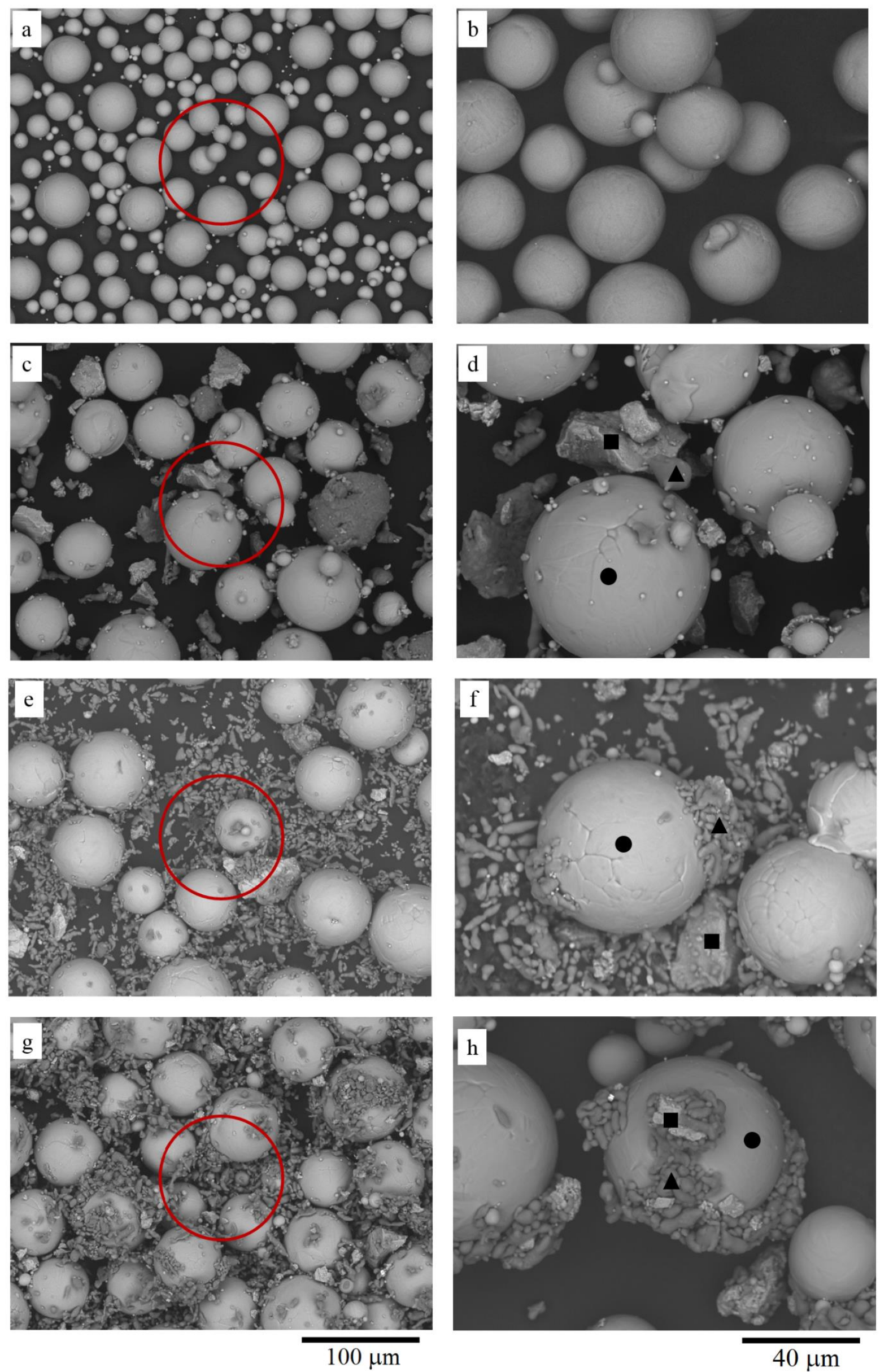
Figure 1: Backscatter SEM micrographs showing: a) and b) the morphology and the typical size of the pre-alloyed Ti6Al-4V powders. The distribution of $\mathrm{Ti}, \mathrm{Al}, \mathrm{V}$ in the simply-mixed 1 and 2 feedstocks are also shown in c), d) and e), f) respectively. Examples of the satellited powder mixture are instead shown in $\mathrm{g}$ ) and $\mathrm{h}$ ). Red circles represent a toscale schematic of the expected melt pool size. The solid black circles, triangles and squares in d) and $\mathrm{f}$ ) indicate $\mathrm{Ti}$, $\mathrm{Al}$, and $\mathrm{V}$ powders, respectively.

The melt pool size determines the scale of scrutiny required to examine the powder feedstocks, as during the deposition of successive layers, the local composition in the solid remains invariant owing to the limited diffusional distances of the elements in the solid state [22]. Figure 1a-b depict the typical pre-alloyed Ti-6Al-4V powders of the reference feedstock. As expected, the particles have uniform spherical morphology consistent with that previously reported in works on plasma atomised pre-alloyed Ti-6Al-4V [23].

Samples from the powder batches produced using the simple-mixing approach are shown in Figure 1c-d and e-f. Figure 1c-d reveal that mixing elemental powders of similar size distribution (simplymixed 1) led to mixtures that are not satisfactory to the SLM scale of interest, as regions where the specific elements segregate ( $\mathrm{Ti}$ or $\mathrm{Al}$ in particular due to their relative abundance) were evident. Figure 1 e-f depict powder mixture formed by simply-mixing elemental $\mathrm{Ti}$ with $\mathrm{Al}$ and $\mathrm{V}$ powders of smaller size distribution (simply-mixed 2). At the SLM scale of interest, relative large areas abundant in $\mathrm{Al}$ were observed. This result is in agreement with the observations on the feedstock created by mechanically-mixing different elements $[7,14]$. Figure $1 \mathrm{f}$ shows that random Ti particles are decorated by Al clusters. The adhesion mechanism is subject of ongoing research.

The powder mixture produced using the satelliting mixing process is presented in Figure $1 \mathrm{~g}-\mathrm{h}$. In comparison to the simply mixed, a higher proportion of $\mathrm{Al}$ and $\mathrm{V}$ particles bonded to the surfaces of the $\mathrm{Ti}$ particles. The presence of some large-sized V particles, however, led to some V particles acting as carriers, producing areas rich in $\mathrm{Al}$ and V. Similar to that reported in [20], the number of "satellites" on the Ti particles varies, which is most likely a consequence of the irregular size and morphology of the particles and insufficient wet mixing. It can be observed however that the introduction of a bonding agent to the mix causes the powder mixture to acquire a cohesive character where small powders, no longer as mobile as in the free-flowing simply-mixed feedstock, decorate larger particles.

The flowability of the produced batches was assessed using the hall flowmeter funnel following the ASTM standard B213-13. The pre-alloyed powder showed the best flow rate at $32.4 \pm 0.5 \mathrm{~s} / 50 \mathrm{~g}$. This can be attributed to the smooth spherical morphology and the powder's uniform size distribution. The powder batch produced by simple mixing and satelliting (both using fine $\mathrm{Al}$ and $\mathrm{V}$ particles) showed flow rates of $40 \pm 1$ and $36.12 \pm 0.07$, respectively. Better powder flowability suggests improved processability as the process requires successive deposition of uniform layers of powder and poor flowability is expected to hinder this. 


\subsection{Characterisation of the microstructure of the samples processed from different feedstocks}

An overview of the microstructure of the samples SLM processed from the four different feedstocks is shown in Figure 2.
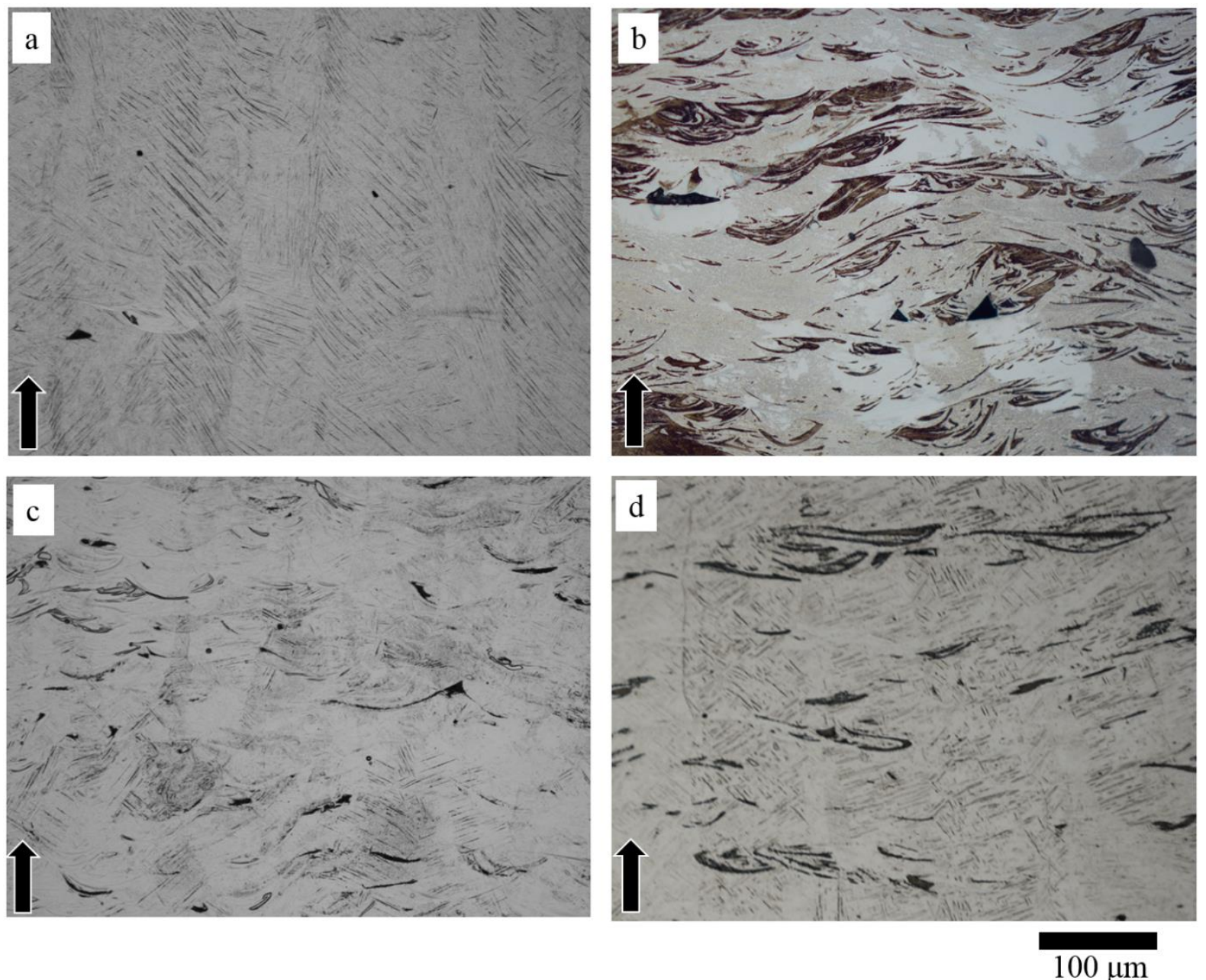

Figure 2: Optical micrographs showing the typical microstructure of the frontal plane of the samples deposited from pre-alloyed (a), simply-mixed 1 feedstock (b), simply-mixed 2 feedstock (c), and satellited feedstocks (d). The building direction (z-axis) is indicated by the black arrows in the micrographs.

In Figure 2a the typical microstructural features of the as-built Ti-6Al-4V produced from pre-alloyed powders can be seen. As established in numerous prior works on the subject [5, 24], the microstructure consists of a single $\alpha$ ' martensitic phase forming acicular grains formed in prior- $\beta$ columnar grains. Image analysis of the sample cross-sections reveals that the samples fabricated from the pre-alloyed powders had a density of $99.7 \%$ ( \pm 0.1 standard deviation).

The microstructure of the parts deposited from feedstock obtained by simply mixing elemental powders of similar size distribution (simply mixed 1), shown in Figure 2b, presented quite significant different traits. Although there were no un-molten particles visible, indicating a successful melting of the powder-bed, the grain structure of the deposited samples was not clearly delineated, with no 
evident prior- $\beta$ columnar grains or acicular $\alpha / \alpha^{\prime}$ grains showing in the etched micrograph. Instead, wavy regions that etched at different rates can be observed suggesting significant compositional variations in the structure. The average density of the samples was $98.2 \%$ ( \pm 0.2 standard deviation).

The microstructure of the SLM samples produced from the feedstocks obtained by i) mixing and ii) satelliting Ti with $\mathrm{Al}$ and $\mathrm{V}$ of smaller particle size distribution are shown in Figure $2 \mathrm{c}-\mathrm{d}$. These consist of visible prior- $\beta$ columnar grains and martensitic laths, resembling those seen in the case of SLM of pre-alloyed Ti-6Al-4V. Although to a lesser degree than that observed in Figure $2 b$, swirling areas etched at different rates are also observed suggesting elemental segregation. The average densities of the samples manufactured from the simply-mixed and satellited feedstock are 99.2 and $99.1 \%$, respectively ( \pm 0.1 standard deviation). As the process parameters were kept constant during the manufacturing of the samples shown in Figure 2, differences in the density and microstructure are caused by a different response of the powder-bed to the laser energy input. This will be discussed in more detail in Section 4.

The phase composition of the samples deposited from the four different feedstocks was further investigated by XRD (Figure 3). 


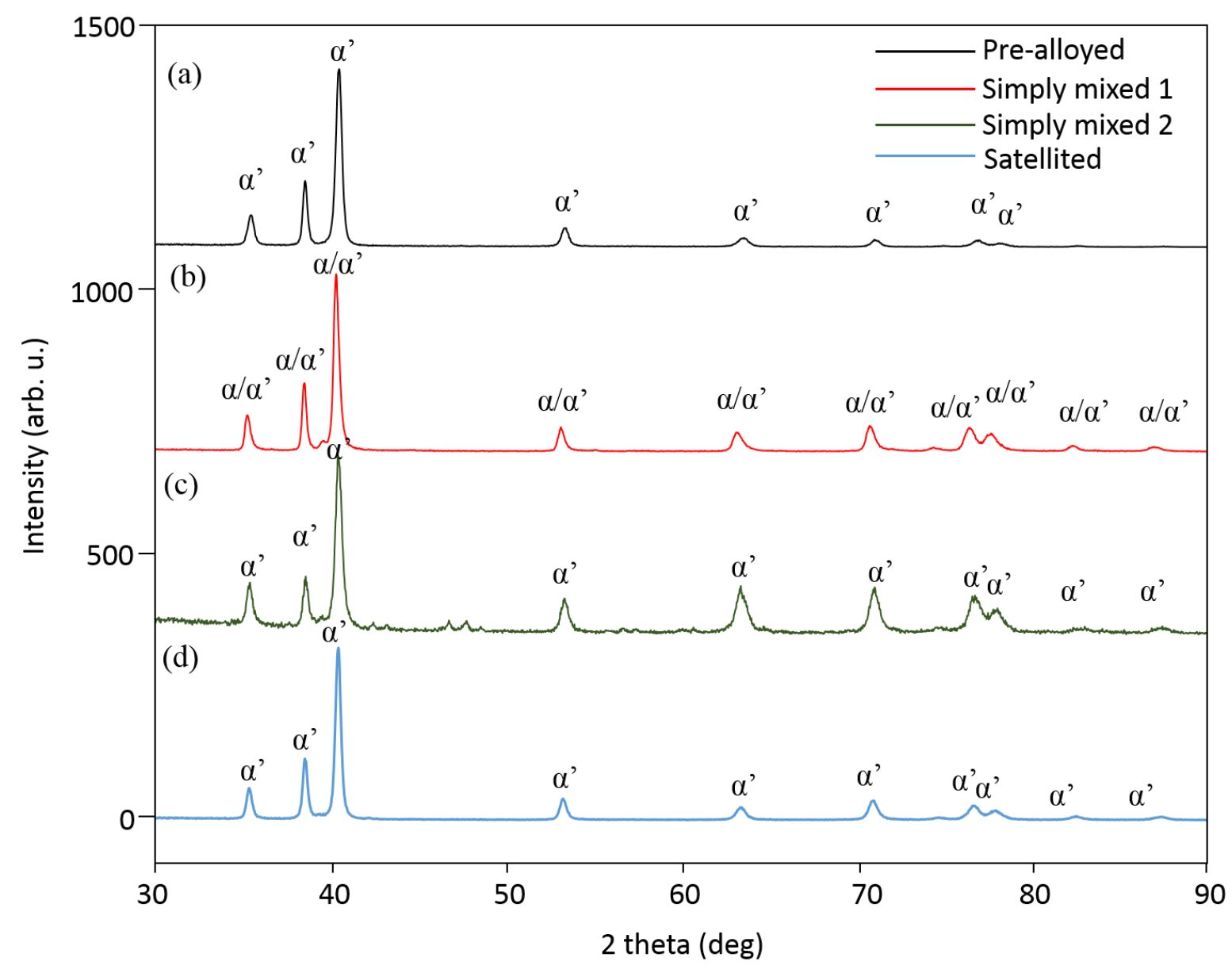

Figure 3: Comparison of the XRD spectra obtained from samples deposited from the: a) pre-alloyed, b) and c) simply-mixed, and c) satellited powder feedstocks.

The deposit built from pre-alloyed Ti-6Al-4V showed diffraction peaks corresponding to the hexagonal close-packed (hcp) Ti phase (PDF card 00-044-1294) (Figure 3a). There is general consensus that SLM of pre-alloyed Ti-6Al-4V results in $\alpha$ 'martensitic microstructures where the allotropic phase transformation from a body-centered cubic (bcc) $\beta$ structure to a hcp $\alpha$ structure of CP Ti occurs by diffusionless shear and dilatation, so the diffraction peaks observed in Figure $3 \mathrm{a}$ are attributed to the $\alpha$ 'martensitic phase.

The XRD spectra associated to the samples deposited from the mixed and satellited feedstock reveal that their microstructure consisted also of hcp Ti phase (Figure 3b-c) with no detectable retained $\beta$ phase or intermetallics. It was observed that some of the hcp Ti reflections in the sample built from the simply-mixed feedstock appear at lower $2 \theta$ locations than those measured on the samples manufactured from the pre-alloyed or satellited powders. This suggests that the microstructure of the deposit built from the simply-mixed feedstock might consist of a mixture of $\alpha / \alpha$ ' phases [25] as opposed to the other samples, built from pre-alloyed and satellited feedstocks, that would share similar martensitic solidifications. Nevertheless additional transmission electron microscopy (TEM) investigations are required to confirm these considerations. The variation in the peak intensity across the spectra is negligible indicating no significant texture difference in the samples. 
The grain structure and elemental distribution of the sample deposited from the simply-mixed 1 powders is shown in Figure 4.

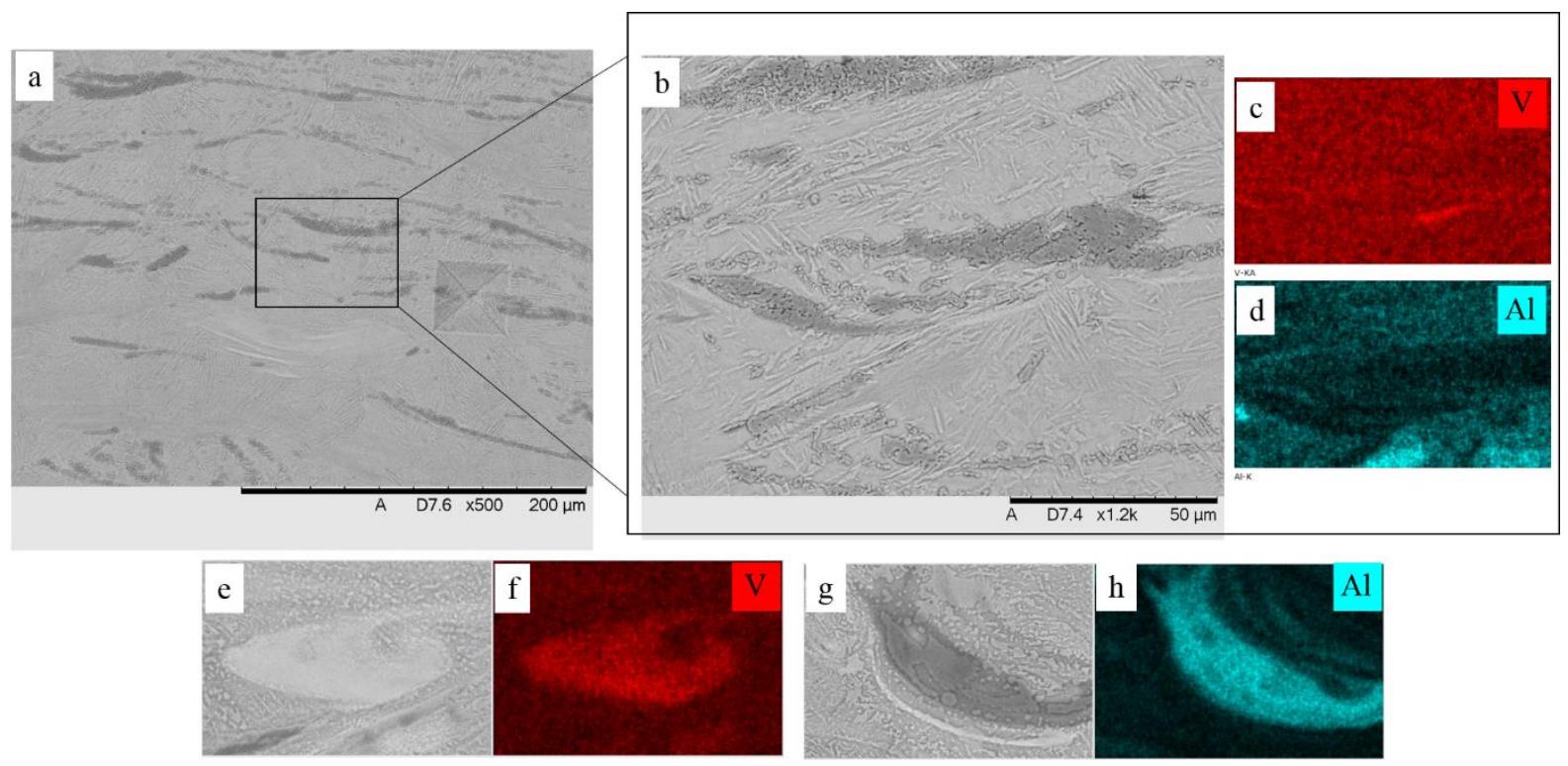

Figure 4: Backscatter SEM/EDS showing the general microstructural features of the sample built from simply mixed 1 feedstock.

The vast majority of the grain structure has a plate-like morphology with grains coarser than that typically reported for SLM of pre-alloyed Ti-6Al-4V [5]. Despite the grain structure being relatively uniform, the $\mathrm{Al}$ and $\mathrm{V}$ content in the $\alpha / \alpha^{\prime}$ grain structure (Figure $4 \mathrm{a}-\mathrm{b}$ ) varied from 0.5 to $7 \mathrm{wt} . \%$ and 0.4 to 1 wt.\%, respectively. This inhomogeneity in chemical composition is likely to have caused over-etching in some areas of the microstructure, as shown in Figure 2b. The dark striations consisting mainly of $\mathrm{Ti}(>99 \mathrm{wt} . \%)$ are randomly distributed in the sample without a significant correlation with melt pools created by the process. Their structure is not clearly resolved (Figure 4b), likely due to a refinement in the grain structure. The microstructure also presents areas of irregular morphology where a severe segregation of $\mathrm{Al}$ and $\mathrm{V}$ has occurred. The $\mathrm{Al}$ rich areas (Figure $4 \mathrm{c}-\mathrm{d}$ ) in these samples contained 15 to $25 \mathrm{wt} . \% \mathrm{Al}$ and only traces of $\mathrm{V}(<0.3 \mathrm{wt} . \%)$ were detected. In the $\mathrm{V}$ segregations (Figure 4e-f), the V content ranges from 10 to 25 wt.\% with 1-2 wt.\% Al. Diffraction analysis (not included in this manuscript) revealed that these areas display the parent structure of either $\mathrm{V}$ or $\mathrm{Al}$ but these phases do not contribute to the XRD spectrum presented in Figure 2b, being present only in minor volume fractions.

The grain structure and elemental distribution of the sample deposited from simply-mixed 2 feedstock is reported in Figure 5. 


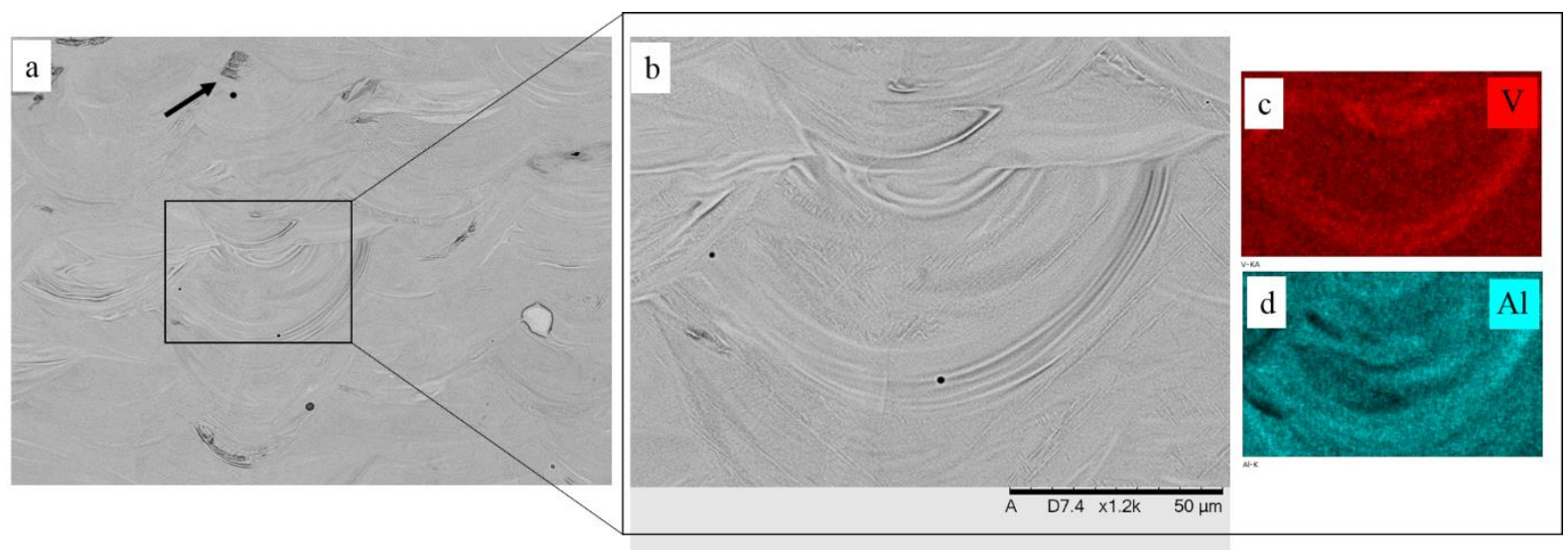

Figure 5: Backscatter SEM/EDS showing the general microstructural features of the sample built from simply mixed 2 feedstock.

The grain structure is refined and relatively more homogenous than in the previous case. The majority of the microstructure resembles that of SLM pre-alloyed Ti-6Al-4V, with criss-crossed acicular $\alpha$ ' grain structure of different orientations and elongated prior- $\beta$ grain boundaries aligned with the building direction. Striations enriched in Ti are also present in the sample (arrow in Figure 5a) but to a lower extent in composition to that observed in Figure 4. Melt pool boundaries are well delineated and, as seen in Figure 5b-d, enriched in $\mathrm{Al}$ and V. There was no evidence of un-molten Al, which despite the high reflectivity and thermal conductivity, likely melts when in contact with molten $\mathrm{Ti}$ during the process. Relatively large areas, consisting predominately of $\mathrm{V}$, were however observed in the structure (areas of light contrast in Figure 5).

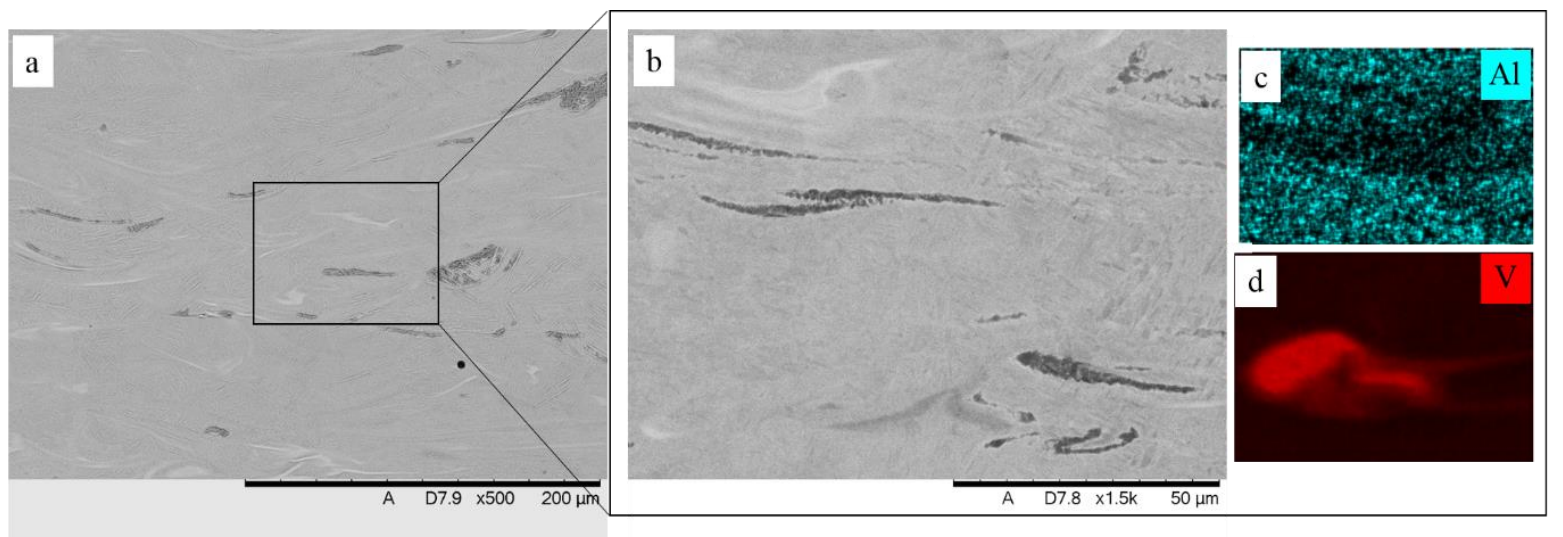

Figure 6: Backscatter SEM/EDS showing the general microstructural features of the sample built from satellited feedstock.

The microstructure of the sample produced from the satellited feedstock is shown in Figure 6. Overall, the grain structure is comparable to that shown in Figure 5. The $\mathrm{Al}$ and $\mathrm{V}$ distribution in the acicular grain structure is closer to the target Ti-6Al-4V composition with $\mathrm{Al}$ and $\mathrm{V}$ ranging from 3 to $5 \mathrm{wt}$.\% and 2 to $3.4 \mathrm{wt} . \%$, respectively. As in the previous case, dark striations appear in the structure. The chemical analysis suggests that $\mathrm{Ti}$ is the preferential element that segregates in these areas (Ti content $>98 \%$ ) similar to that observed in the sample originated from the simply-mixed 1 feedstock. 
Severe segregation of the alloying elements was also observed in these samples although melt pool boundaries are not easily discernible. Finally, relatively large segregations of V were also evident in the microstructure (red areas in Figure $5 \mathrm{~b}$ and closer view in Figure 5e-f); the composition of these areas consisted predominantly of $\mathrm{V}(>87 \mathrm{wt} . \%)$ and Ti.

The micro-hardness of the sample deposited from pre-alloyed powders was $353 \pm 13 \mathrm{HV}$. This hardness value is comparable to that reported for pre-alloyed Ti-6Al-4V built by SLM in the literature, which typically varies between 350-500 HV [24]. The samples built from simply-mixed 1 and satellited feedstocks, with average hardness of 253 and $299 \mathrm{HV}$, respectively, have a hardness significantly inferior to the pre-alloyed deposits. These variations in hardness reflect the observed changes in the microstructure, as demonstrated by the fact that the sample of coarser grain structure and higher porosity is also the softest. In addition, it is observed that the samples obtained from the mixed feedstocks show the largest hardness deviations, likely caused by the inhomogeneous composition and distribution of the alloying elements measured in the microstructure. Interestingly, the sample built from simply mixed 2 feedstock shows a hardness of $355 \pm 13$ HV directly comparable to those obtained from pre-alloyed Ti-6Al-4V, indicating a refined microstructure and improved homogeneity.

\section{Discussion}

In-situ alloying has the potential to significantly increase the number of materials that can be manufactured by AM in general and SLM in particular, especially facilitating the design of new alloy formulations capable of leveraging the unique solidification dynamics imposed by the process as well as improving productivity. In order to obtain parts with uniform structure and properties, however, it is crucial to prepare feedstocks with controlled compositions at the melt pool level, i.e. the length scale at which the alloy is synthesised. This is always the case when processing pre-alloyed feedstocks, as these feedstocks guarantee a perfect mixture of the alloy constituents at any point in the powder blend, but it remains a challenging aspect for the feedstocks prepared by mixing heterogeneous elemental powders.

Simple-mixing of free-flowing powders (where the inter-particle forces are negligible) produces, at best, a random mixture where the composition at any point of the blend can only be statistically predicted. In reality, during the mixing of such powders it is likely that particles tend to group together, yielding a segregated mixture, particularly when particles of different sizes are combined. Despite the absence of an ordering force that would actively cause particles to change position, particle size, shape, density, and resistance to motion are factors that naturally encourage biased grouping of similar particles. This phenomenon was observed in Figure 2c-d, where assessing the 
distribution of the elements at the melt pool length scale, it is possible to discern areas richer in Ti or $\mathrm{Al}$ and is a commonly reported issue in the studies on simple-mixing of heterogeneous powders [7, $14,17]$.

The satelliting mixing technique was evaluated in this research to reduce the tendency of the elements to segregate. This is generally accomplished by forming "ordered units" that repeat in the mixture as described in relevant studies on the formulation of ordered mixtures for pharmaceutical and powder technology applications [26, 27]. Firstly, fine powders are mixed with free-flowing coarser ones. The natural segregation of the small particles is then hindered by the addition of a binding agent that, by generating attractive forces on the smallest particles enables them, upon mixing, to adhere to the coarser carrier powders. Figure $2 \mathrm{f}$ shows the formation of a unit where Ti (base material) is decorated with $\mathrm{Al}$ and $\mathrm{V}$. Nevertheless, in the present study, the mixing process is not entirely successful as $\mathrm{Al}$ agglomerates and $\mathrm{V}$ particles not adhering to the Ti carriers are still visible in the feedstock (Figure 2e). This is believed to be the result of insufficient fine-scale wet mixing and the presence of relatively large $\mathrm{V}$ particles (in comparison to $\mathrm{Ti}$ ) that could not coat the base material and, in some instances, could have acted as carriers for Al. Further investigation on the optimisation of the satelliting process for SLM, involving techniques to achieve better binding, is required and ongoing by the authors.

The densification of SLM parts has been investigated thoroughly in recent years. For a given homogenous powder-bed, good quality parts are formed for those laser parameter combinations (laser power, laser scan speed, beam size, laser hatching) that can ensure conduction-mode melting of the powders and a portion of the pre-existing solid layer below [28]. The present study was carried out using process parameters that approached such an optimal melting regime for pre-alloyed Ti-6Al-4V with powder size distribution, as detailed in the methodology (Section 2.1).

The simply-mixed 1 feedstock presents two main differences that are believed to have caused improper melting and the observed increase in porosity. Firstly, the observed segregation of the alloying elements might have created areas in the powder-bed with thermophysical properties different from that of Ti-6Al-4V. In turn, poor laser coupling is likely to have occurred in these regions of the powder-bed. Secondly, simply-mixed 1 feedstock consisted, on average, of larger particles in comparison to the pre-alloyed reference, causing a spreading of layers of lower powderbed density. This might have impacted the energy absorbance of the powders and, as a consequence, their melting regime.

The intermediate porosity levels observed in the parts obtained from the simply mixed 2 and satellited feedstock could thus be related to the lower extent of elemental segregation and a wider particle size distribution observed in the feedstock. 
The differences in the melting regime and the peculiarities of the feedstocks also have a significant impact on the microstructure of the deposited parts. The typical microstructure of the parts deposited from pre-alloyed Ti-6Al-4V was relatively uniform consisting of the $\alpha^{\prime}$ martensitic phase, which formed from prior $\beta$ columnar grains that develop due to the strong directional heat loss typical of the process. The samples deposited from the simply-mixed feedstock presented instead a mixture of equiaxed and columnar prior- $\beta$ grain boundaries indicating a relative decrease in the heat loss directionality. The negative enthalpy of mixing associated with the synthesis of Ti-Al-V (not necessarily at the target composition) [29] generates additional radial heat in the melt pool that, in turn might have triggered the formation of mixed prior- $\beta$ grain morphologies $[29,30]$. However, this was not the case for the samples deposited from the simply mixed 2 and satellited feedstock that only displayed columnar prior- $\beta$ grain morphologies. This suggests that the enthalpy of mixing is just one of the factors affecting the solidification of the alloys which is believed to be also significantly dependant on the energy absorbance of the powder-bed, as discussed above.

This is also manifested in the average grain size displayed by the deposits. Under the same melting mode, it is broadly accepted that the cooling rates during SLM are proportional to the thermal gradients between the melt pool and its surroundings and the solidification rate [31]. By increasing the temperature of the melt pool, exothermic enthalpy of mixing would cause a further increase in the thermal gradients and yield microstructural refinement [30]. This was not reflected in the coarser grain size of the sample obtained from simply-mixed 1 feedstock suggesting again that this powderbed has absorbed a small amount of the laser energy input resulting in a significantly different melting mode.

The chemical composition of the SLM deposits built from pre-alloyed Ti-6Al-4V is uniform with only limited elemental portioning at the scale of the grain structure. The findings of this study indicate instead that the chemical composition of the parts deposited from the mixed elemental powders is not uniform neither inside the individual melt pools nor across different locations in the samples (i.e. multiple melt pools). Etching of the cross-section of the sample deposited from the simply-mixed 1 feedstock revealed indeed wavy areas (at times connecting several melt pools) that possessed different compositions to the surrounding material (Figure 2b). These areas appeared to have a random distribution in the cross-section reflecting the inhomogeneity of the starting powder material. Although still existing, similar areas were less evident in the samples deposited from the simplymixed 2 and satellited feedstock (Figure 2c-d). The relatively large Al- and V-rich segregates found in the sample deposited from the elemental mixture might account for the alloying element depletion observed in the laminar microstructure, although it is likely that preferential evaporation of elements might have occurred during processing.

No straightforward correlation is observed between melt pool location and the segregation of one of the alloy constituents. Occasionally, the melt pool bottom boundaries are enriched in $\mathrm{Al}$ or V (Figure 
5) and this contrasts with the hypothesis that Ti being heavier than $\mathrm{Al}$ and $\mathrm{V}$ would segregate at the bottom of the pool near the fusion line. Consistent with that reported in other studies [12, 14], segregation at this scale might be an unavoidable signature of in-situ alloying. Although the mixing of the alloy constituents is encouraged by the Marangoni convective currents, rapid solidification and different properties of the elements (such as density, viscosity and melting temperature) affect the distribution of the elements in the melt [12].

This work confirms that achieving microstructural homogeneity in samples deposited from feedstocks of mixed elemental powders is an important aspect to be considered. Parts with a random dispersion of the elements/phases are indeed likely to display undesirable properties and might be corrected only by ad-hoc homogenisation heat treatments.

To minimise particle percolation during simple-mixing, elemental powders of narrow size distribution should be used. Nevertheless this implies powder-bed spreading and packing that differ from that typically desired in SLM. As observed in the present study, this might lead to a different energy absorbance which, in turn, could potentially mask the real effect of the alloying additions to the microstructural formation. The satelliting mixing process offers an interesting new approach to the realisation of a more uniform powder feedstock that, in principle, could facilitate research on alloy design for powder-based metal AM. During satelliting mixing, the dispersion of the alloying elements is facilitated by combining particles of wide size distribution whilst particle percolation is minimised by creating "ordered" units consisting of a carrier (base metal) and satellites (alloying elements).

Future research will focus on experimental methodologies to improve the homogeneity of the satellited mixtures and offer guidelines for the preparation of suitable feedstocks for in-situ alloying during SLM.

\section{Conclusions}

This study contributes to the understanding of in-situ alloying of elemental powder mixtures during SLM. Three elemental powder mixtures of Ti-6Al-4V were formed. Simply-mixed feedstocks were created by mechanically mixing the elements in the weight proportions of the target composition. A satellited feedstock was prepared by mixing the alloy constituents using a novel satelliting mixing approach. These feedstocks were then used to manufacture specimens for microstructural characterisation and for direct comparison against the pre-alloyed counterparts. Based on the obtained results the following can be concluded:

1) the elemental mixtures presented particle segregation and were not homogeneous at the scale of the melt pool characteristic of the process (here assumed to be $\sim 100 \mu \mathrm{m}$ based on the scan track width). Satelliting or mechanically mixing alloy-base metal powders (Ti) with fine alloy constituents $(\mathrm{Al}$ and $\mathrm{V})$ produce feedstocks that lead to the manufacture of samples with 
microstructural features similar to that of pre-alloyed Ti-6Al-4V.

2) The microstructures of the samples deposited from the tested feedstocks differed in a number of features. The samples deposited from the simply-mixed 1 feedstock displayed the highest porosity, the coarsest grain structure, and severe segregation. This indicates that during processing, this feedstock was subject to a different melting and solidification mode. The microstructure of the satellited feedstock is, overall, similar to that typically observed in SLM of pre-alloyed Ti-6Al-4V although undesired elemental segregations are still present. More research to establish the relationship between physical properties of the material, particle size distribution, and binding agent is required to fine-tune this innovative powder mixing technique.

3) The inhomogeneity of the starting feedstock results in an overall random distribution of the segregates in the microstructure that can only be reduced by post-processing homogenisation treatments.

The study presents the satellite mixing technique as an innovative methodology that in the future could potentially enable the formulation of homogenous feedstocks at the scale of interest of powderbed fusion AM. Research on mixing of elemental powders is of growing interest in the AM community to sustain the development of in-situ alloying and the formulation of novel AM-dedicated materials.

\section{Acknowledgements}

The authors would like to thank Mr Kamal Al-Hamdani for his help with the satelliting process. 


\section{References}

[1] I. Gibson, D. Rosen, B. Stucker, Powder Bed Fusion Processes, in: I. Gibson, D. Rosen, B. Stucker (Eds.) Additive Manufacturing Technologies: 3D Printing, Rapid Prototyping, and Direct Digital Manufacturing, Springer New York, New York, NY, 2015, pp. 107-145.

[2] J. Suryawanshi, K.G. Prashanth, S. Scudino, J. Eckert, O. Prakash, U. Ramamurty, Simultaneous enhancements of strength and toughness in an Al-12Si alloy synthesized using selective laser melting, Acta Materialia, 115 (2016) 285-294.

[3] N.T. Aboulkhair, I. Maskery, C. Tuck, I. Ashcroft, N.M. Everitt, The microstructure and mechanical properties of selectively laser melted AISi10Mg: The effect of a conventional T6-like heat treatment, Materials Science and Engineering: A, 667 (2016) 139 146.

[4] A. Riemer, S. Leuders, M. Thöne, H.A. Richard, T. Tröster, T. Niendorf, On the fatigue crack growth behavior in 316L stainless steel manufactured by selective laser melting, Engineering Fracture Mechanics, 120 (2014) 15-25.

[5] M. Simonelli, Y.Y. Tse, C. Tuck, On the Texture Formation of Selective Laser Melted Ti-6AI-4V, Metallurgical and Materials Transactions A, 45 (2014) 2863-2872.

[6] M. Garibaldi, I. Ashcroft, M. Simonelli, R. Hague, Metallurgy of high-silicon steel parts produced using Selective Laser Melting, Acta Materialia, 110 (2016) 207-216.

[7] M.L. Montero Sistiaga, R. Mertens, B. Vrancken, X. Wang, B. Van Hooreweder, J.-P. Kruth, J. Van Humbeeck, Changing the alloy composition of Al7075 for better processability by selective laser melting, Journal of Materials Processing Technology, 238 (2016) 437-445.

[8] M. Simonelli, Y.Y. Tse, C. Tuck, Effect of the build orientation on the mechanical properties and fracture modes of SLM Ti6Al-4V, Materials Science and Engineering: A, 616 (2014) 1-11.

[9] B. Vrancken, L. Thijs, J.P. Kruth, J. Van Humbeeck, Microstructure and mechanical properties of a novel $\beta$ titanium metallic composite by selective laser melting, Acta Materialia, 68 (2014) 150-158.

[10] H. Zhang, H. Zhu, X. Nie, J. Yin, Z. Hu, X. Zeng, Effect of Zirconium addition on crack, microstructure and mechanical behavior of selective laser melted Al-Cu-Mg alloy, Scripta Materialia, 134 (2017) 6-10.

[11] S. Guo, Y. Lu, S. Wu, L. Liu, M. He, C. Zhao, Y. Gan, J. Lin, J. Luo, X. Xu, J. Lin, Preliminary study on the corrosion resistance, antibacterial activity and cytotoxicity of selective-laser-melted Ti6Al4V-xCu alloys, Materials Science and Engineering: C, 72 (2017) 631-640.

[12] I. Yadroitsev, P. Krakhmalev, I. Yadroitsava, Titanium Alloys Manufactured by In Situ Alloying During Laser Powder Bed Fusion, JOM, 69 (2017) 2725-2730.

[13] C. Qiu, A. Fones, H.G.C. Hamilton, N.J.E. Adkins, M.M. Attallah, A new approach to develop palladium-modified Ti-based alloys for biomedical applications, Materials \& Design, 109 (2016) 98-111.

[14] P. Vora, K. Mumtaz, I. Todd, N. Hopkinson, AISi12 in-situ alloy formation and residual stress reduction using anchorless selective laser melting, Additive Manufacturing, 7 (2015) 12-19.

[15] B. Zhang, N.-E. Fenineche, H. Liao, C. Coddet, Microstructure and Magnetic Properties of Fe-Ni Alloy Fabricated by Selective Laser Melting Fe/Ni Mixed Powders, Journal of Materials Science \& Technology, 29 (2013) 757-760.

[16] N. Kang, P. Coddet, L. Dembinski, H. Liao, C. Coddet, Microstructure and strength analysis of eutectic Al-Si alloy in-situ manufactured using selective laser melting from elemental powder mixture, Journal of Alloys and Compounds, 691 (2017) $316-322$. [17] A. Grigoriev, I. Polozov, V. Sufiiarov, A. Popovich, In-situ synthesis of Ti2AINb-based intermetallic alloy by selective laser melting, Journal of Alloys and Compounds, 704 (2017) 434-442.

[18] A. CLARE, A. Kennedy, Additive manufacturing, Google Patents, 2015.

[19] K.S. Al-Hamdani, J.W. Murray, T. Hussain, A. Kennedy, A.T. Clare, Cold sprayed metal-ceramic coatings using satellited powders, Materials Letters, 198 (2017) 184-187.

[20] A.N.D. Gasper, S. Catchpole-Smith, A.T. Clare, In-situ synthesis of titanium aluminides by direct metal deposition, Journal of Materials Processing Technology, 239 (2017) 230-239.

[21] Standard Terminology for Additive Manufacturing-Coordinate Systems and Test Methodologies.

[22] N.J. Harrison, I. Todd, K. Mumtaz, Reduction of micro-cracking in nickel superalloys processed by Selective Laser Melting: A fundamental alloy design approach, Acta Materialia, 94 (2015) 59-68.

[23] M. Simonelli, C. Tuck, N.T. Aboulkhair, I. Maskery, I. Ashcroft, R.D. Wildman, R. Hague, A Study on the Laser Spatter and the Oxidation Reactions During Selective Laser Melting of 316L Stainless Steel, Al-Si10-Mg, and Ti-6AI-4V, Metallurgical and Materials Transactions A, 46 (2015) 3842-3851.

[24] L. Thijs, F. Verhaeghe, T. Craeghs, J.V. Humbeeck, J.-P. Kruth, A study of the microstructural evolution during selective laser melting of Ti-6Al-4V, Acta Materialia, 58 (2010) 3303-3312.

[25] D. Gu, Y.-C. Hagedorn, W. Meiners, G. Meng, R.J.S. Batista, K. Wissenbach, R. Poprawe, Densification behavior, microstructure evolution, and wear performance of selective laser melting processed commercially pure titanium, Acta Materialia, 60 (2012) 3849-3860.

[26] J.A. Hersey, Ordered mixing: A new concept in powder mixing practice, Powder Technology, 11 (1975) 41-44.

[27] M. Alonso, M. Satoh, K. Miyanami, K. Higashi, T. Ito, Regular electroconductive networks made from metal-coated plastic powders: Effect of the concentration of metal on the conductivity, Powder Technology, 63 (1990) 35-43.

[28] W.E. King, H.D. Barth, V.M. Castillo, G.F. Gallegos, J.W. Gibbs, D.E. Hahn, C. Kamath, A.M. Rubenchik, Observation of keyhole-mode laser melting in laser powder-bed fusion additive manufacturing, Journal of Materials Processing Technology, 214 (2014) 2915-2925.

[29] T. Hua, C. Jing, Z. Fengying, L. Xin, H. Weidong, Microstructure and Mechanical Properties of Laser Solid Formed Ti-6Al-4V from Blended Elemental Powders, Rare Metal Materials and Engineering, 38 (2009) 574-578.

[30] K.I. Schwendner, R. Banerjee, P.C. Collins, C.A. Brice, H.L. Fraser, Direct laser deposition of alloys from elemental powder blends, Scripta Materialia, 45 (2001) 1123-1129.

[31] X.P. Li, J. Van Humbeeck, J.P. Kruth, Selective laser melting of weak-textured commercially pure titanium with high strength and ductility: A study from laser power perspective, Materials \& Design, 116 (2017) 352-358. 